\title{
Universal Assumptions of Aristotle's Methodology Related to Nature
}

\author{
Jerzy Kosiewicz* \\ Department of Philosophy and Sociology, Josef Pilsudski University of Physical Education in Warsaw, Poland
}

Received: 阱 August 17, 2018; Published: 海 August 30, 2018

*Corresponding author: Jerzy Kosiewicz, Department of Philosophy and Sociology, Josef Pilsudski University of Physical Education in Warsaw, Poland

\section{Mini Review}

In the ancient Greek culture and philosophy statements about the world had cosmological and cosmogonic character. The first were totally (like, for example, in Thales', Anaximander's, Heraclitus' philosophy) or partially connected with inductive assumptions (e.g. in Pythagoreans', Plato's or Aristotle's statements). On the other hand, the second had always metaphysical (that is, mythical) nature of religious (like in Orphism), quasi-religious (like in Pythagoreanism) or secular (like in views of Plato - in spite of the fact that he referred to religious myths - as well as in Aristotle's and Epicurus' works) character.

In Aristotle's statements about the empirically perceptible world (the cosmos) there are two main methodological currents the inductive (empirical) one and the empirical one - concerning the following findings:

a) Those of ideographic (descriptive, based also on induction on inductive reasoning) character,

b) Those interpreting sense, essence, principles and reasons in an intuitive way. The first two kinds of findings inspired and made it possible to formulate.

c) Intuitive statements of nomotetic character - that is, those explaining construction and functioning of the universe and taking the form of deductive syllogisms.

That is the sequence which comes from Aristotle's considerations included in "Metaphysics". The precondition for proper description and explanation of existence and functioning of the cosmos is understanding that the foundations of the universe are constituted by a supernatural being in the form of the necessary Unmoved, Prime, Eternal Mover or the First Cause, the divine Reason and God, who is a living, continuous and the optimal being, a very self-existent act (1071a-1073a).

Thus, the pivotal aim of the first science (that is, the first philosophy); of philosophical theory or, in other words, the philosophy of the universe (cosmos); of theological astronomy or of astrophysical philosophy - which simultaneously constitutes a specification of the philosophy of nature and an exposition of a significant part of Aristotle's philosophy of myth - is the proper formulation and groundwork of the ideal (divine) foundation of metaphysics of the universe.

The abovementioned methodological currents can be described as:

a) The metaphysical one; that is - in that case - the intuitive one, which has mythical (or, if interpreted more broadly, mythological) character, which constitutes the foundation of the deductive syllogism - that is, deductive reasoning;

b) The inductive one, based on external experience - that is, on extraspection and the inductive syllogism.

The discussed currents constitute together methodological assumptions of universal or just global character. They refer both to the ancient Greek as well as to the contemporary philosophy of the universe.

At first Aristotle proclaims, on the basis of induction that is, the inductive syllogism -that the cosmos exists and then he explains in an intuitive, metaphysical and mythical way (that is, on the basis of the deductive syllogism) - how existence and functioning of the universe is possible. He creates a significant, very deep and noteworthy philosophy of myth. God appears in it as a being who is immanent in its relation towards the world and transfers to it its power, divinity, immortality, eternity, constant and incessant movement and life in a hylozoist meaning. The Stagirite emphasizes that nature - which exists eternally - is totally divinized and theized (from $\theta \varepsilon$ ó - god), because it is all saturated with incessantly eternal divinity, God's qualities and abilities. Thus, its essence is divine and hence there exist permanent sacralization, divinization and theization of substances and things of non-confessional, secularly metaphysical character. 
Aristotle points also out to difficulties connected with reliable explanation and understanding of existence and functioning of the universe. In his times they led every philosopher to cognitive perplexity. "Now he who wonders and is perplexed feels that he is ignorant (thus the myth-lover is in a sense a philosopher, since myths are composed of wonders)" (982b). That who refers (as for example Plato) to myths saturating Greek culture or creates myths describing and explaining nature and qualities of supranaturalist - abstract, metaphysical or divine beings in the context of a philosophical paradigm (of non-religious character, as in the case of Aristotle) is a representative of the philosophy of myth. That myth simultaneously points out to cognitive limitations of the human individual, philosophy and science.

The abovementioned philosophy of myth included, among others, in Aristotle's "Metaphysics" and Plato's metaphysics is a philosophy justifying existence of supernatural beings and making use of the scheme of mythical thinking based on rational and irrational thinking. Both in the first and in the second case the final conclusions concerning the existence of God have irrational character, because they are based on intuition and a connected metaphysical hypothesis which cannot be currently confirmed. It means that regardless the applied context of justification: a rational or an irrational one the certainty of God's existence is not going to be proved.

The philosophy of myth and a methodology applied by the Stagirite has universal and global character in that sense that it concerns all independent idealist philosophies and philosophies of religious character, regardless culture as well as place and time of their coming into being. It comes from the fact that it constitutes a significant contribution to reflection on assumptions of general methodology and a source of inspiration for various external specialized methodologies of all philosophical disciplines, as well as all scientific disciplines of theoretical, inductive and applicative character.

Universal and global character is also characteristic for an Aristotelian epistemological and simultaneously methodological assumption pointing out to agnosticism, to limitations of human cognitive abilities, which underlie the great Stagirite's philosophy of myth. It was referred to by, among others, David Hume (1947; 1963; 1974). Paul Feyerabend $(1970 ; 1975 ; 1979)$ emphasized, inter alia,

\section{ISSN: 2574-1241}

\section{DOI: $10.26717 /$ BJSTR.2018.08.001669}

Jerzy Kosiewicz. Biomed J Sci \& Tech Res

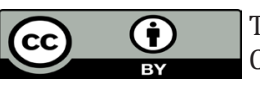

This work is licensed under Creative Commons Attribution 4.0 License

Submission Link: https://biomedres.us/submit-manuscript.php epistemological relativism, nonexistence of final cognitive and methodological criteria as well impossibility of creation of certain knowledge. One of forms taken by criticism of cognitive abilities is radical methodological agnosticism (Kosiewicz 1995, pp. 297-301; Kosiewicz 1996, pp. 275-287). It points out somehow after Aristotle that it is impossible to work out such theoretical and instrumental assumptions which would make it possible to reach and gain knowledge about the universe in the final and irrefutable form. In the face of magnitude of that what can be described, explained and understand, and with instruments which contemporary society has at its disposal, one can feel like a cognitive ignorant (not only in the philosophical sense).

A metaphysical (the term "metaphysical" refers not to its content but to formal assumptions) hypothesis which is fundamentally connected with his philosophy of the cosmos has also similar character, because it is widely applied in natural sciences. It refers, for example, to astrophysics of Hawking, Strominger and Perry, because they hypothetically assume that on the horizon of black holes there are electromagnetic records in the form of soft hair including data concerning, among others, hundreds of billions of stars (with their possible planetary systems) which were consumed by those holes. That they will be reproduced, what will make it possible to maintain continuity of macrogigantic and smaller thus, of all physical systems.

They do not assume - unlike Aristotle in his monograph "On Coming-to-Be and Passing-Away" (1981) that thing irretrievably pass away and turn into nonentities, into nothingness. Neither do they share the view included in Albert Einstein's and Stephen Hawking's statements (presented in Hawking's texts: Hawking 1974a; Hawking 1974b) which try to prove that black holes undergo total annihilation - together with physical systems they have consumed - as a result of continuous emitting and losing energy (Hawking 1974a; Hawking 1974b). The main Hawking's, Strominger's and Perry's hypothesis (together with the connected partial, fragmentary or stage hypotheses) concerns something what will possibly come into existence, but it will never be possible to be confirmed or falsified by philosophers and scientists from our solar system. Referring to Leszek Kołakowski's theory, we can say that that type of conceptions (with included hypotheses) have, after all, character of an astrophysical myth which is extremely attractive from the cognitive point of view.

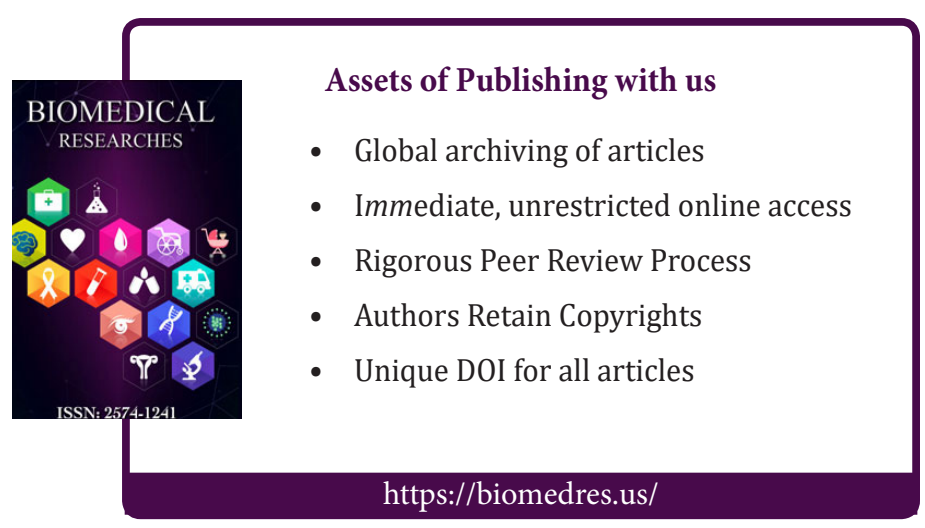

Cite this article: Jerzy Kosiewicz. Universal Assumptions of Aristotle's Methodology Related to Nature. Biomed Sci\&Tech Res 8(3)- 2018. 